\title{
Integrating process simulation and MINLP methods for the optimal design of absorption cooling systems
}

Juan A. Reyes-Labarta ${ }^{1}$, Robert Brunet ${ }^{2}$, José A. Caballero ${ }^{1}$, Dieter Boer ${ }^{3}$ and Laureano Jiménez²

\section{CONIREUION}

- Novel framework for the design of sustainable themodynamic cycles.

- Combined use of process simulation tools (Aspen Hysys and Aspen Plus), optimization software (Matlab) and LCA.

- The problem is mathematically fomulated as multiobjective mixed-integer non-linear programming (moMINLP) problem.

- Two different themodynamic cycles are optimized a 10MW Rankine power cycle and a $100 \mathrm{~kW}$ waterammonia absorption cooling cycle.

\section{INTRODUCTION}

- Energy consumption is one of the main factors affecting global waming. Over the last 25 years has inc reased world wide by $\mathbf{6 6} \%$

- The energy is usually produced by power plants, mainly Rankine cycles, which operate by the combustion of fossil fuels. Moreover, conventional a ir conditioning systems a re based on compression cycles which require mechanic al energy for its operation

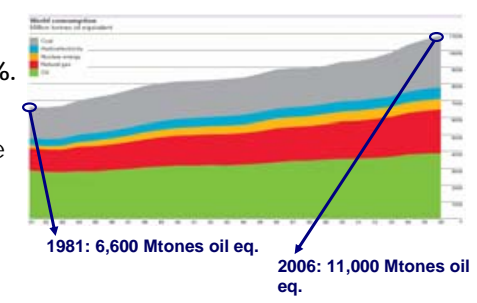

- Clearneed to introduce new technologies. Develop a systematic method for the optimal design of thermodynamic cycles based on the combined use of process simulation and optmization tools

\section{MEIHODOLOGY}

\subsection{MATHEMATICALFORMUIATION}

\section{Problem Statement}

- Rankine cycle. Given are: the flowsheet a ragement (Moran and Shpiro, 1993), the net power yield, turbines and pump efficiencies, the overall heat transfer coeffic ents, themodynamic properties, cost estimation correlations, economic parameters and environmental indicators. -Absorption Cycle. Given are: the cooling capacity, the inlet and outlet temperatures of the extemal fluids.

- Objetive: determine the optimal process design for the minimization of the total annualized cost and the corresponding environmental impact (Ec 099).

\section{Formulation}

- The design of thermodynamic cycles with environmental concems can be formulated as a moMINIP problem :

$$
\begin{aligned}
& \min z=\left\{f_{1}\left(x, u, x_{D}\right), \ldots, f_{n}\left(x, u, x_{D}\right)\right\} \\
& h_{I}\left(x, u, x_{D}\right)=0 \\
& h_{E}\left(x, u, x_{D}\right)=0 \\
& \left.g_{E}\left(x, u, x_{D}\right) \leq 0\right\}
\end{aligned}
$$

\subsection{SOLUION PROCEDURE}

- The solution of optimization problem is given by a set of Pareto optimal process designs

- The proposed algorithm iterates between master and primal subproblem. 1) We solve the problem via the epsilon constraint method.

2) The primal subproblem is solved with fminc on implemented in Matlab NLP.

3) The master MILP problem is solved with CPLEX using GAMS.

4) The algorithm solves iteratively both subproblems until the two temination criteria are satisfied.

The algorithm presented takes around 1,000 CPU sec onds and around 3,000 CPU seconds to generate 10 Pareto solutions for the Rankine cycle and absorption cycle respectivelty, on a computer AMD PhenomTM 8600B, Triple-Core Processor $2.29 \mathrm{G} \mathrm{Hz}$ and $3,23 \mathrm{~GB}$ of RAM.

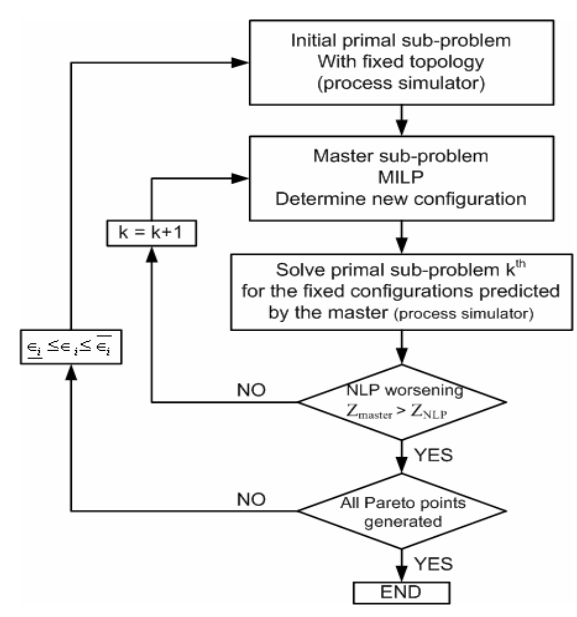

\section{RESULISAND DISCUSSION}

\subsection{CASE SIUDY IF SIEAM RANKIN E CYCIE}

The cycle provides $10 \mathrm{MW}$. The main process units are Boilers 1 and 2 (B1, B2), turbines 1-4 (K1, K2, K3, K4), condenser (C), pumps 1,2 (P1, P2) and a shell-tube heat exchanger (HX). The cycle also includes two splitters (T1, T2) an expansion valve (VLV1) and a mixer (MX1)-
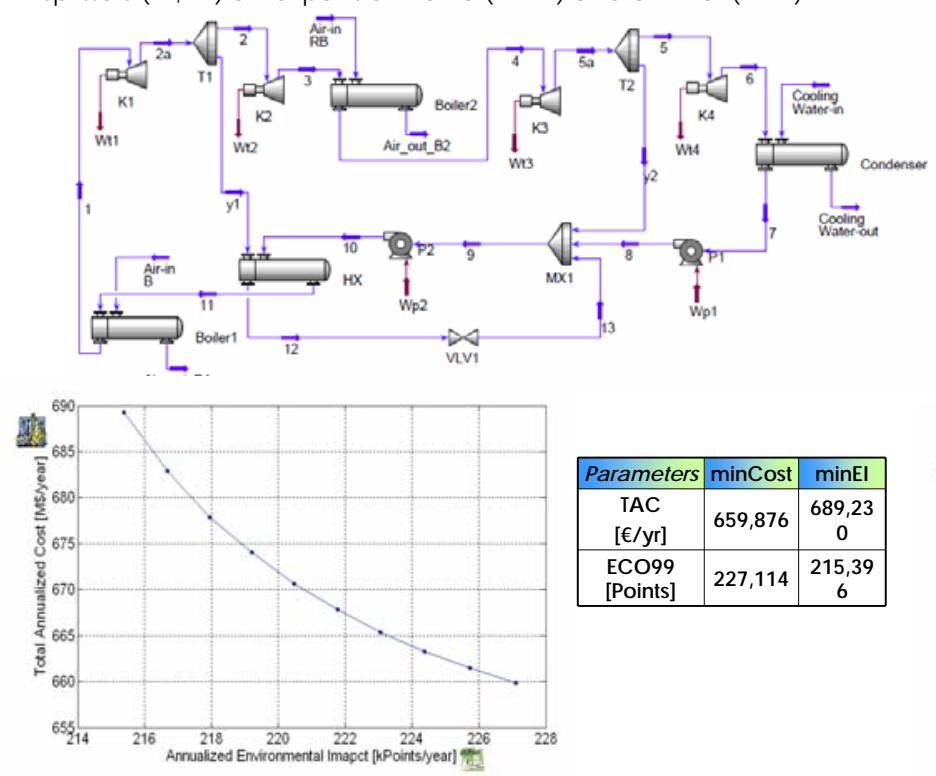

\section{CONCLUSIONS AND FUTURE WORK}

-This work presents a novel framework for the design of sustainable thermodynamic cycles. -Both case studies were validated with existing models and optimized from these base points. Obtaining improvements of the cycle, which reduces the total annualized cost and environmental impact.

\subsection{CASE SIUDY II: ABSORPIION COOING CYCIE}

The system provides chilled water for cooling applications. The basic components are the absorber (A), condenser (C), the desorber column (D), and evaporator (E). The cycle also includes the refrigerant subcooler (SC), refrigerant expansion valve (RV), solution heat exchanger (SHX), solution pump (P), and solution expansion valve (SV).

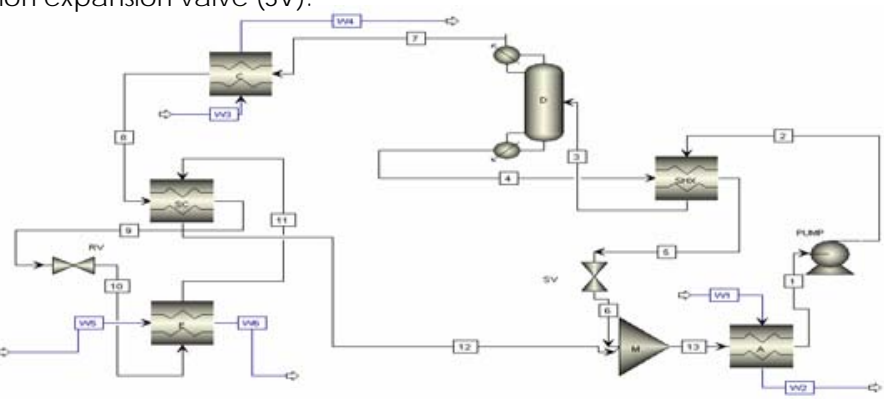

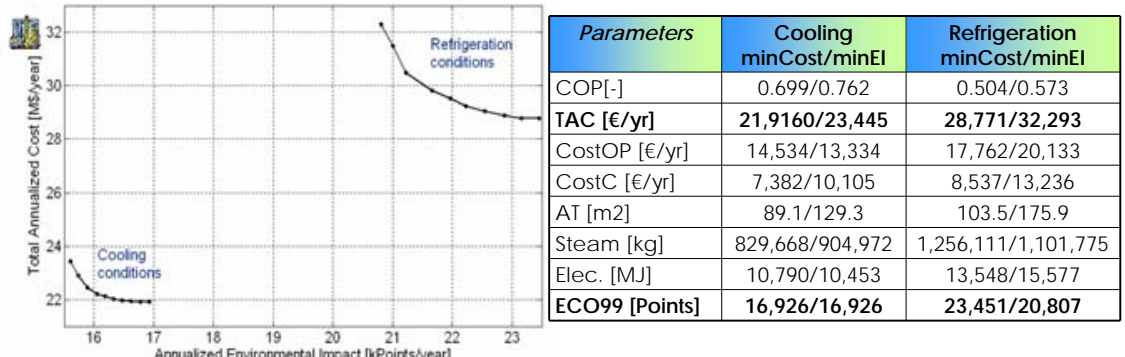

\section{ACKNOWLEDGMENTS}

- The authors wish to acknowledge support from the Consellería de Educación of the Generalitat Valenciana (BEST/2010/085) and Ministerio de Ciencias e Innovación (PPQ, CTQ2009-14420C02) 